\title{
Good practice in the early years
}

This is the third edition of the Sheffield Hallam team book and it addresses a range of key issues in the field of early years, with particular focus on the English context. The title is bold, yet Janet Kay's opening chapter serves to dissipate any concerns regarding this as she interrogates head on the challenges of defining and engaging in 'good practice in the early years' and includes a distinct aim for the book: 'to offer students and existing practitioners a discussion of various aspects of practice' (3). Alongside a wholly appropriate focus on principles and values, the editor's introductory chapter provides a strong foundation for this eclectic text. Nine chapters follow, each focused on a different aspect of the field of early years.

Chapter 1 is concerned with Play in Early Years Education. Philippa Thompson considers a good range of points but given the contested area of play and learning, deeper-level interrogation of some points may be beneficial. In her chapter on Children's Rights and Participation, Ann Kellock provides a sound introduction to the subject matter but more explicit coverage of some key tensions might be helpful to readers - for example, the juxtaposition of protection and participation rights. Ann Kellock and Jonathan Wainwright consider Reflective Practice in the third chapter and the range of reflective models they introduce is likely to prove valuable to students and practitioners, though it would be good to see the focus on reflective practice in work with children extended to work with families and colleagues. A particular strength of this chapter is its consideration of limitations of reflection.

Penny Borkett's chapter on Diversity and Inclusion in the Early Years covers some important issues though there might have been merit in extending the discussion about defining inclusion, given the difficulties inherent in doing so. Moreover, even in the months since the book's publication, significant policy changes have been mooted in the area of inclusion in England; this may indicate the need for a fourth edition! In the chapter that follows, Karen Hardy considers the important area of young children Growing and Developing. Perhaps the breadth of this aspect is the reason why consideration of curriculum and pedagogy tends to remain rather underdeveloped. Nevertheless, the main areas of child development are covered, which will prove especially useful for student readers.

Sarah Procter focuses on Promoting Young Children's Health for Chapter 6. Whilst the chapter would benefit from more up-to-date texts to support points, valuable consideration of definitions of health is provided alongside discussion concerning well-chosen, relevant issues. In Chapter 7, Rosemary Furey addresses Child Protection and Safeguarding Issues and provides some thought-provoking reflection points. Important focus is given to online child protection issues and for undergraduate students the section on 'Processes following a referral to children's social care services' may prove particularly useful. Damien Fitzgerald's chapter on Working with Parents and Families provides comprehensive coverage of an area of early years' work that can prove especially challenging to inexperienced students and practitioners. His consideration of the dynamic of the parent-practitioner relationship is likely to be valuable to undergraduate students. The final focus area for the book is Multi-Agency Working. Jonathan Wainwright gives important focus to the challenges of multi-agency working though undergraduate students might find links to other literature useful. We are reminded of the value of the Early Years Professional role in multi-agency working for children but this serves as a further indication that a fourth edition may be needed. 
In her conclusion, Janet Kay wisely reiterates that Good Practice in the Early Years is far more than a simple skill set and she rightly emphasises the importance of quality, values and a holistic approach to working with young children. Overall, the book would benefit from greater engagement with surrounding literature to support claims, to model what is required of undergraduate students and to direct readers to the wider field of early childhood. Nevertheless, the text has much to offer those who are new to the field or have just begun to study within it: the range of issues covered will prove valuable and features such as case studies will support understanding about how readers might navigate those issues within the provisional context of 'good practice in the early years'. 